\title{
Influência do Método de Fenação e Tempo de Armazenamento sobre a Composição Bromatológica e Ocorrência de Fungos no Feno de Alfafa (Medicago sativa, L. cv. Flórida 77) ${ }^{1}$

\author{
Jussimara Manoela Nascimento ${ }^{2}$, Ciniro Costa $^{3}$, Antônio Carlos Silveira ${ }^{3}$, Mário De Beni Arrigoni ${ }^{3}$
}

RESUMO - O experimento objetivou estudar a influência de 24 tratamentos resultantes do arranjo fatorial 6 x 4, referente a seis métodos de fenação e quatro tempos de armazenamento em delineamento inteiramente casualizado, com cinco repetições para análise bromatológica e quatro para determinação de fungos. Os métodos de fenação consistiram em: T1 - (sombra, E) secagem à sombra, a forrageira foi levada para o galpão imediatamente após o corte e mantida espalhada (E); T2 e T3 - o material permaneceu ao sol até perder $50 \%$ do peso e posteriormente foi seco à sombra, sendo o T2 espalhado (sol 50\%, E) e o T3 amontoado - A (sol 50\%, A); T4 e T5, consistiram do recolhimento da forragem para completar sua secagem à sombra, após viragem e perda de $60 \%$ de peso sob exposição ao sol, T4 espalhada (sol 60\%, E), T5 amontoada (sol 60\%, A) e o T6 perda de 80\% do peso sob exposição ao sol e posteriormente amontoado à sombra (sol $80 \%, \mathrm{~A})$. Os quatro tempos de armazenamento foram: 0, 15, 30 e 60 dias. Verificou-se que os fenos nos quais o material ficou mais tempo exposto ao sol apresentaram pior qualidade em termos de PB, FDN e FDA. A ocorrência de fungos foi maior no feno seco à sombra (T1) e naqueles em que a forragem foi amontoada, devido à ausência de aeração para retirada de umidade. O método mais adequado para a conservação da alfafa consistiu na exposição da forragem ao sol até a perda de $50 \%$ do peso da forragem original, com posterior secagem do material espalhado à sombra.

Palavras-chave: alfafa, armazenamento, composição bromatológica, fenação, feno, fungo

\section{Haying Method and Storage Length Effects on Chemical Composition and Mold Growth on Alfalfa Hay (Medicago sativa, L. cv. Florida 77)}

\begin{abstract}
The objective of this experiment was to study the influence of six haying and four storage periods on the chemical composition and mold growth of alfafa hay. A 6x4 factorial arrangement was used in a completely randomized design, with five replicates for chemical analyses and four replicates for mold determinations. The haying methods were: T1- (shade, S) shade-drying; the forage was carried to a barn immediately after cutting and spreaded (S); T2 and T3: the material was sun-dried until a 50\% weight loss and was shade-dried thereafter; T2 was spreaded (sun 50\%, S) and T3 was piled up (sun 50\%, P). Treatments T4 and T5 consisted of sun-drying and revolving the forage until a $60 \%$ weight loss and then completing the drying process under shade, with the material either spreaded (T4, sun $60 \%, \mathrm{~S}$ ) or piled up (T5, sun $60 \%, \mathrm{P})$. T6 consisted of sun-drying until an $80 \%$ loss and then piling up under shade (sun $80 \%$, P). The four storage periods were: $0,15,30$ and 60 days. It was observed that the hays originating from the longest sun-drying periods showed the worst quality in terms of CP, NDF and ADF. Mold occurrence was highest in the shade-dried hay (T1) and also in the piledup material, due to lack of ventilation necessary for moisture removal. The most adequate method for alfalfa conservation consisted of sun-drying the forage until a $50 \%$ weight loss, followed by shade-drying of the spreaded material.
\end{abstract}

Key Words: alfalfa, chemical composition, hay, haying, mold, storage

\section{Introdução}

Em virtude de seu excelente valor forrageiro, aliado ao seu hábito de crescimento ereto e rápido desenvolvimento, a alfafa tem sido usada de diversas maneiras nas distintas regiões do mundo. No momento ideal de corte, em que a alfafa apresenta de 10 a $20 \%$ de florescimento ou a rebrota na base da planta atinge em torno de $5 \mathrm{~cm}$ de altura, a cultura possui 75 a $80 \%$ de umidade, que deve ser criteriosamente reduzida para adequada conservação na forma de feno e silagem (COSTA e MONTEIRO, 1997).

O processo de fenação da alfafa deve ser cuidadoso, pois a secagem excessiva ao sol provoca a queda das folhas, que, apesar de corresponder, em média, a menos de $50 \%$ do peso total do feno, contém cerca de $70 \%$ da proteína e $90 \%$ do caroteno (LAMBERT e JANIKE, s/d).

Uma das alternativas para diminuir os riscos de perdas, devido à ocorrência de chuvas durante a cura

\footnotetext{
${ }^{1}$ Parte da Dissertação de Mestrado do primeiro autor à FMVZ, UNESP - Campus de Botucatu.

2 Zootecnista.

3 Professor da Faculdade de Medicina Veterinária e Zootecnia, UNESP, Cx. 560, 18618-000 - Botucatu, SP. E.mail: secdmna@fca.unesp.br
} 
do material a campo, e evitar a secagem excessiva e perda de folhas, seria efetuar parte da secagem ao sol e completá-la em galpão. HART e BURTON (1967) registraram perdas de $30 \%$ de matéria seca durante a secagem da alfafa a campo, sendo que $10 \%$ foram atribuídos à respiração e $20 \%$, à perda de folhas. Entretanto, a demora da secagem em galpão, dependendo das condições climáticas, pode acarretar no desenvolvimento de fungos.

No armazenamento, COLLINS et al. (1987) relataram que as perdas são atribuídas à respiração e atividade de microorganismos no feno e, estas são de 2 a $5 \%$ da matéria seca do feno, que segundo ROTZ e ABRAMS (1988), a maioria das perdas ocorrem dentro de 30 dias de armazenamento. A população de fungos sofre alteração acentuada havendo diminuição daqueles gêneros típicos de campo como Fusarium e Cladosporium e aumento de Aspergillus e Penicillium de maior ocorrência durante o armazenamento (HLODVERSSON e KASPERSSON, 1986).

Dessa forma, o objetivo deste trabalho foi avaliar a influência dos métodos de secagem natural (ao sol e à sombra) para a produção de feno de alfafa (Medicago sativa L.) de alta qualidade, por meio de análise bromatológica, e a ocorrência de fungos logo após a confecção do feno e durante o armazenamento, procurando determinar o método mais apropriado para a fenação da alfafa.

\section{Material e Métodos}

O experimento foi conduzido na fazenda As Grevilhas, município de Botucatu-SP, para determinar os efeitos da secagem da alfafa (Medicago sativa $\mathrm{L}$. cv. Flórida 77), ao sol e à sombra, sobre a composição bromatológica e o desenvolvimento de fungos no feno.

O corte foi realizado no dia 11 de março de 1997, às 9 horas, quando a forrageira estava com 34 dias de crescimento, com 10 a $20 \%$ de florescimento. A produtividade era de $10 \mathrm{t}$ de matéria verde por hectare e cada tratamento correspondeu a uma área de $400 \mathrm{~m}^{2}$.

O experimento constou de 24 tratamentos resultante do arranjo fatorial $6 \times 4$, referente a seis métodos de fenação e quatro tempos de armazenamento, em delineamento inteiramente casualizado, com cinco repetições para análise bromatológica e quatro para determinação de fungos. Os métodos de fenação consistiram em: T1 - (sombra, E) secagem à sombra, a forrageira foi levada para o galpão imediatamente após o corte e mantida espalhada (E); T2 e T3 - o material permaneceu ao sol até perder $50 \%$ do peso $\mathrm{e}$, posteriormente, seco à sombra, sendo o $\mathrm{T} 2$ espalhado (sol 50\%, E) e o T3 amontoado (sol 50\%, A); os tratamentos T4 e T5 consistiram do recolhimento da forragem para completar sua secagem à sombra, após viragem e perda de $60 \%$ de peso sob exposição ao sol, T4 espalhada (sol 60\%, E) e T5 amontoada A ( sol 60\%, A); e o T6 consistiu na perda de $80 \%$ do peso sob exposição ao sol e, posteriormente, amontoado à sombra $($ sol $80 \%, \mathrm{~A})$. Os quatro tempos de armazenamento foram $0 ; 15 ; 30$; e 60 dias.

A perda de peso das amostras durante a secagem ao sol foi monitorada com o emprego de balança. Considerou-se o ponto de feno quando o material apresentava peso constante, em média de 96 a 144 horas, para o material que permaneceu espalhado e amontoado, respectivamente. Nos tratamentos em que a forragem permanecia espalhada à sombra, a espessura era ao redor de $30 \mathrm{~cm}$. Diariamente efetuava-se a viragem do material em todos os tratamentos.

A alfafa foi enfardada com enfardadeira estacionária, em fardos retangulares de peso médio de $10 \mathrm{~kg}$ e, em seguida, transportada e estocada por 60 dias em um galpão da Faculdade de Medicina Veterinária e Zootecnia (FMVZ), Campus de Botucatu.

As amostragens foram efetuadas nos quatro tempos de armazenamento para avaliação da composição bromatológica e ocorrência de fungos. As análises bromatológicas consistiram na determinação dos teores de proteína bruta $(\mathrm{PB})$ e nitrogênio insolúvel em detergente ácido (NIDA), segundo ASSOCIATION OF OFFICIAL AGRICULTURAL CHEMISTS AOAC (1970), e matéria seca (MS), fibra em detergente neutro (FDN) e fibra em detergente ácido (FDA), segundo SILVA (1990). A relação folhacaule foi efetuada no material original imediatamente após o corte e no tempo 0 de estocagem, que consistiu na retirada de cinco amostras de $20 \mathrm{~g}$ cada. Após a separação em folha e caule, o material foi seco em estufa de circulação forçada de ar até peso constante.

Para o levantamento de fungos presentes no material fenado, utilizou-se o método de contagem total em placas de Petri de material suspenso diluído em série. Amostras de 10 gramas de feno, moído em peneiras de 20 mesh e homogeneizado, foram acondicionadas em frascos Erlenmeyer contendo $190 \mathrm{~mL}$ de solução salina estéril, o qual foi agitado por dois minutos e deixado repousar por 30 segundos, obten- 
do-se, assim, diluição 1:20. Testes preliminares demonstraram que a diluição inicial de 1:10 não foi satisfatória para o feno de alfafa, por ser muito higroscópico. O sobrenadante intermediário foi coletado com pipeta estéril e utilizado no preparo de diluições $10^{-2}, 10^{-3}, 10^{-4}, 10^{-5}$. Alíquotas de 1 $\mathrm{mL}$ das diversas diluições foram inoculadas em placas de Petri estéreis (10 placas por tratamento, diluições $10^{-3}$ e $10^{-4}$ para os tratamentos $\mathrm{T} 1$, T2, T4 e T6, e diluições $10^{-4}$ e $10^{-5}$ para os tratamentos T3 e T5). A seguir, verteu-se o meio de cultura batata-dextrose-ágar (BDA), adicionado de cloranfenicol e rosa bengala, previamente fundido e mantido a $42-45^{\circ} \mathrm{C}$, com agitação leve das placas para homogeneização da amostra. As placas foram vedadas com filme de PVC magic pack, para impedir a desidratação e contaminação ambiental, e incubadas sob regime de luz natural por sete dias à temperatura ambiente. Após o período de incubação, as placas foram examinadas individualmente e realizadas contagens para obtenção do número de Unidades Formadoras de Colônias (UFC) por grama de material. Para cada tratamento, procurou-se isolar em tubos inclinados com batata-dextrose-ágar as espécies fúngicas predominantes ou mais freqüientes.

Lâminas das culturas foram preparadas, coradas com lacto-fenol-azul-algodão e suas estruturas observadas ao microscópio ótico comum e comparadas em BARNETT e HUNTER (1987), para facilitar a identificação.

O meio de cultura batata-dextrose-ágar (BDA) constituiu em: a) colocar $200 \mathrm{~g}$ de batata descascada em $500 \mathrm{~mL}$ de água e cozinhar durante uma hora; b) filtrar o infuso por meio de gaze e completar o volume a $500 \mathrm{~mL}$ com água destilada; c) adicionar $15 \mathrm{~g}$ de ágar, dissolver completamente e então adicionar $10 \mathrm{~g}$ de glicose; e d) distribuir e autoclavar a $120^{\circ} \mathrm{C}$, durante 15 minutos. A solução salina empregada equivaleu à água destilada com concentração de $0,85 \%$ de $\mathrm{NaCl}$.

Para a análise estatística da ocorrência de fungos, os dados foram transformados em $\log \mathrm{x}$, visando homogeneizar as variâncias dos tratamentos, e as médias foram comparadas pelo teste de Tukey, em nível de 5\% de significância.

As condições climáticas de precipitação, temperaturas máximas, média e mínima e umidade relativa do ar, durante o período de fenação e armazenamento do feno, encontram-se na Tabela 1.

\section{Resultados e Discussão}

A análise dos dados das Tabelas 2 e 3 mostra diferença significativa $(\mathrm{P}<0,05)$ entre os métodos de secagem da alfafa sobre a composição bromatológica do feno. Os tratamentos em que o material ficou mais tempo exposto ao sol apresentaram feno de pior qualidade, em termos de PB, FDN e FDA. Tal fato pode ser explicado pela diminuição significativa $(\mathrm{P}<0,05)$ da relação folha/caule com o emurchecimento ao sol. No tratamento em que a forragem permaneceu ao sol até perder $80 \%$ do peso, a sua relação folha/caule $(0,46)$ representou $41 \%$ daquela do material original $(1,12)$.

O teor médio de $44,9 \%$ FDN para o feno de alfafa neste estudo foi superior ao apresentado pelo National Research Council - NRC (1989), 42\% FDN, para alfafa seca ao sol no início do florescimento, enquanto o teor de FDA $(36,12)$ foi ligeiramente superior aos valores apresentados na literatura, que vão desde 22\% (KALU e FICK, 1983), 31\% (NRC, 1989) a 36\% (MERCHEN e SATTER, 1983). As diferenças provavelmente devem-se aos estádios de desenvolvimento da planta e, especialmente, à perda de folhas no processo de secagem, tendo em vista que, segundo LAMBERT e JANIKE (s/d), o processo de fenação da alfafa deve ser cuidadoso, pois a secagem excessiva ao sol provoca a queda das folhas, que correspondem, em média, a menos de $50 \%$ do peso total do feno, porém contém cerca de $70 \%$ da proteína e $90 \%$ do caroteno.

Os teores médios de PB e FDA foram, respectivamente, 29,38 e $18,33 \%$ nas folhas e 12,60 e $50,70 \%$ nos caules (Tabela 4), equivalentes aos encontrados por ALBERT et al. (1989).

Diferença significativa $(\mathrm{P}<0,05)$ ocorreu na composição bromatológica do feno, em termos de $\mathrm{PB}$, FDN, FDA e ADIN, com o tempo de armazenamento, com pequena diminuição especialmente na fase inicial entre 0 e 15 dias. Esta variação se encontra de acordo com ROTZ e ABRAMS (1988), os quais destacaram que a maioria das perdas ocorreram dentro de 30 dias e os conteúdos de FDN e lignina tiveram pequenas mudanças depois do primeiro mês, decrescendo mais tarde durante a estocagem, que durou seis meses. O mesmo não aconteceu na presente pesquisa, provavelmente porque o tempo de estocagem foi menor (2 meses). Segundo os mesmos autores, o aumento inicial da concentração da proteína foi atribuído à perda de constituintes não-protéicos. O total da perda de proteína foi, em média, 6,6\%, sendo similar à perda de matéria seca de todo o feno. 


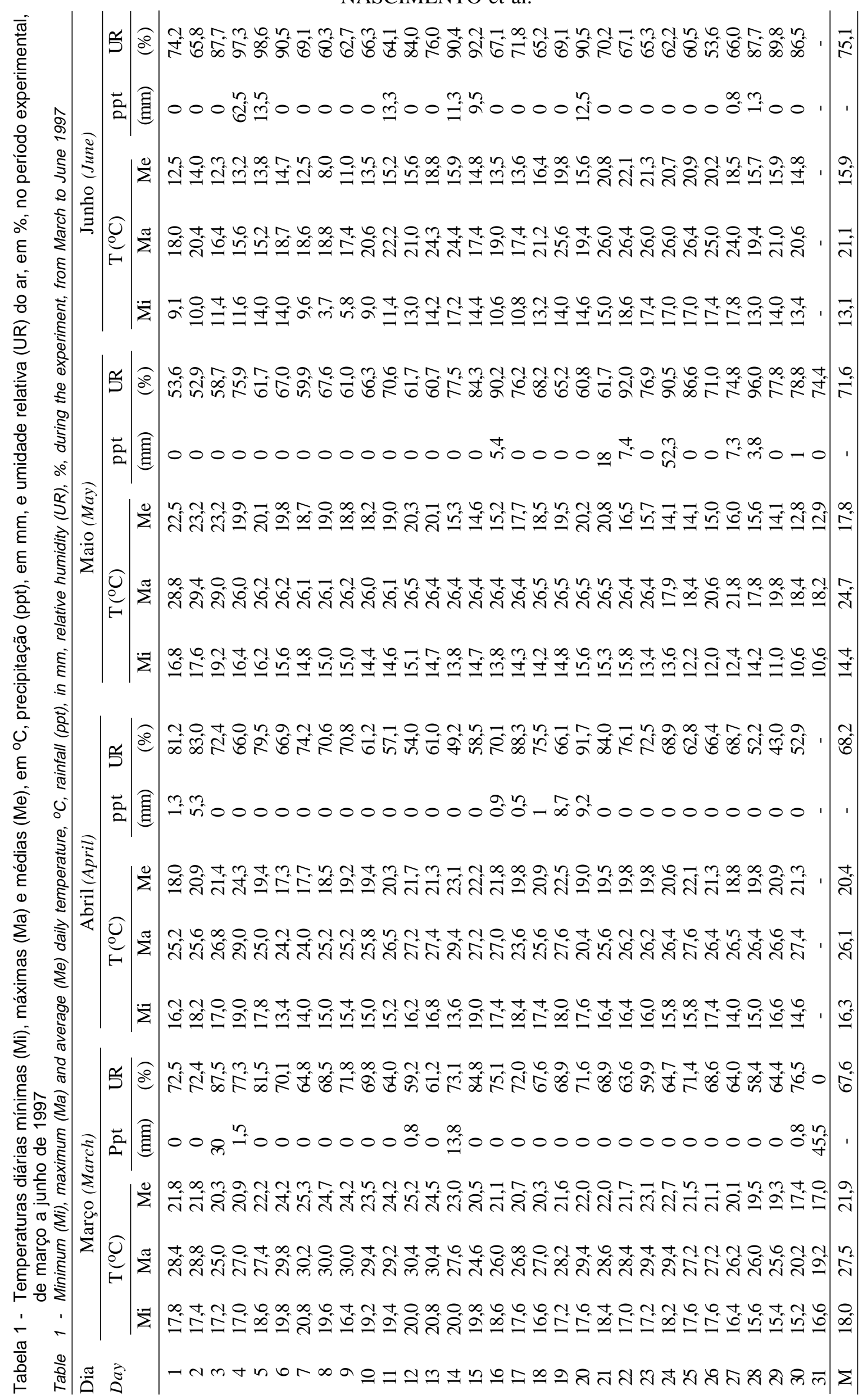


Rev. bras. zootec.

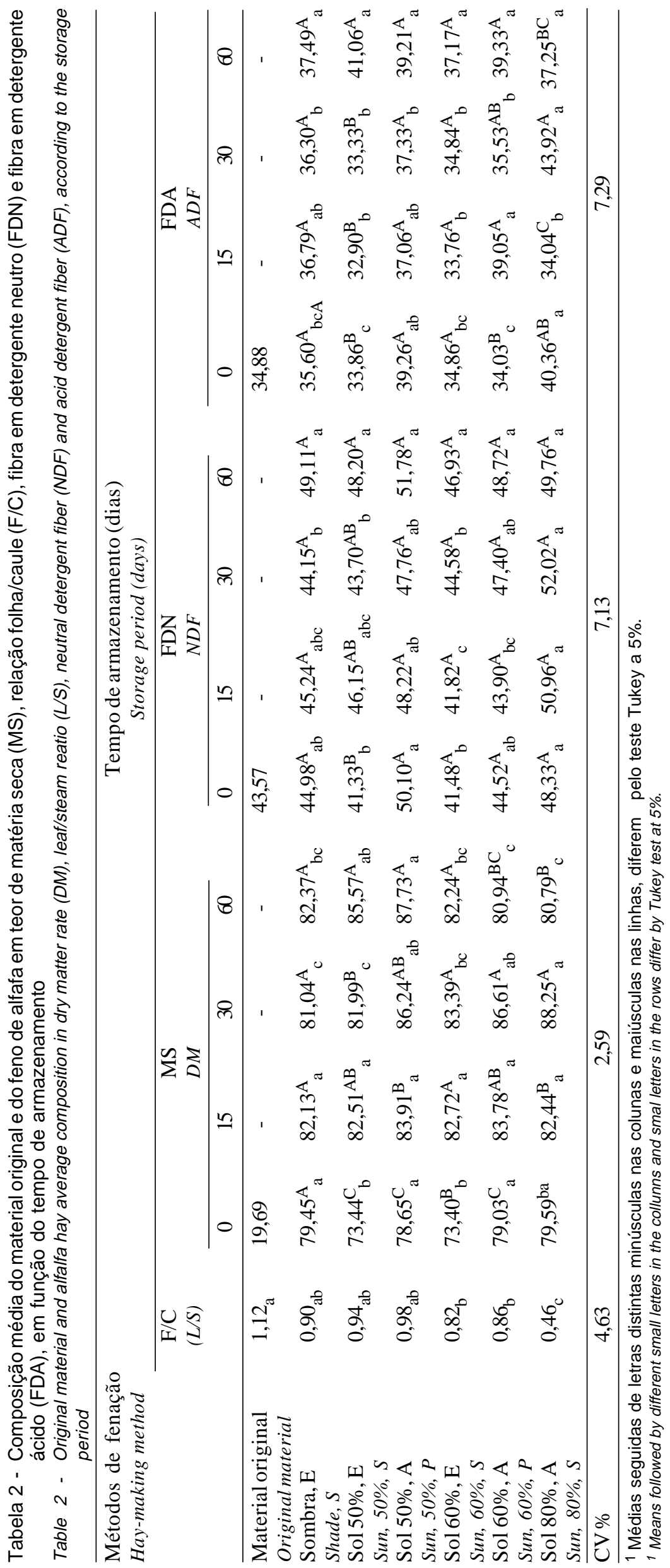


NASCIMENTO et al.

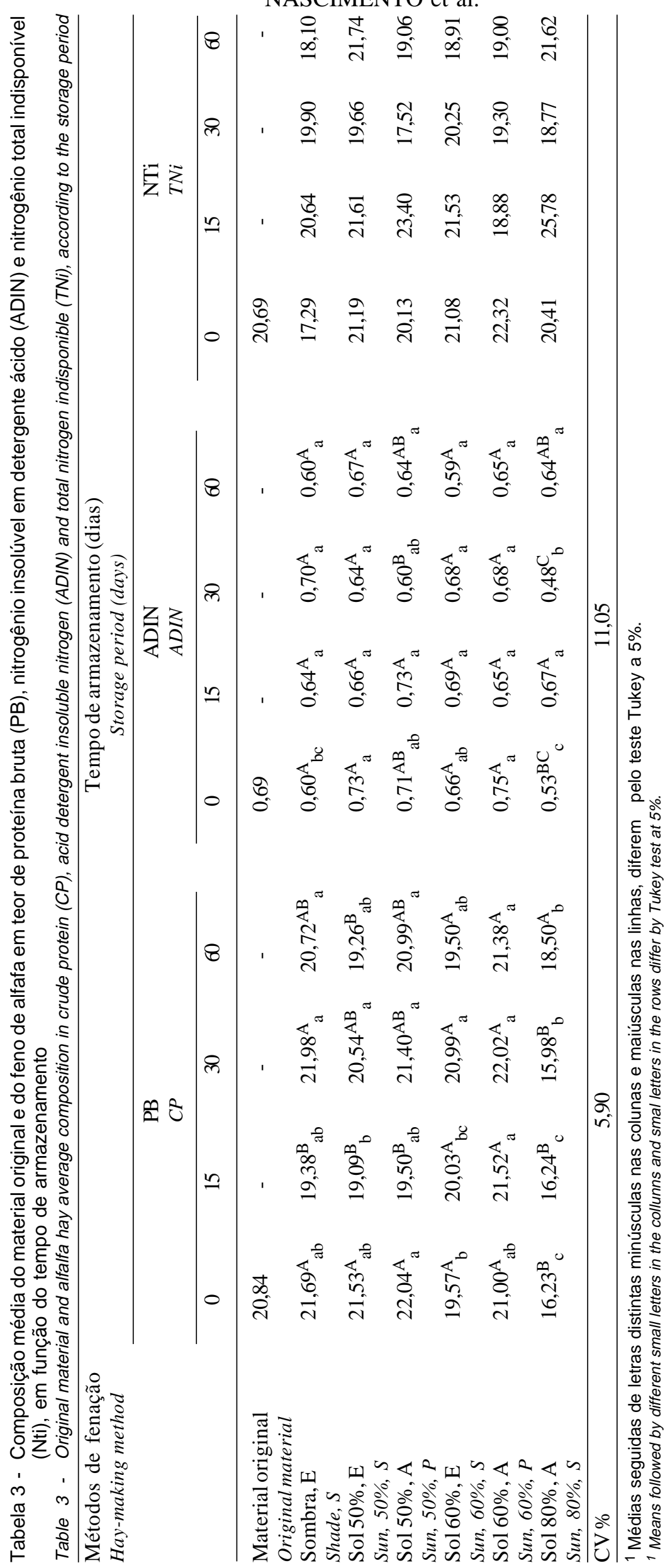


A perda de proteína não estava relacionada com o conteúdo de umidade do feno.

As variações ocorridas no teor de matéria seca $(\mathrm{P}<0,05)$, em função do tempo de armazenamento, podem ser explicadas pelas alterações nas condições climáticas (Tabela 1), o que se explica, segundo RAYMOMD et al. (1978), pelo fato de o feno, por ser higroscópico, absorver e perder água para o ambiente, conseqüentemente, a umidade relativa influencia o teor de umidade da forragem armazenada.

Os baixos teores de nitrogênio insolúvel em detergente neutro em todos os fenos de alfafa, bem como a não-alteração dos mesmos durante os 60 dias de armazenamento, evidencia que os processos foram bem conduzidos. Segundo MOSER (1980) e VAN SOEST (1994), as condições de alta umidade e temperatura acima de $55^{\circ} \mathrm{C}$ são favoráveis à ocorrência de reações não-enzimáticas entre os carboidratos solúveis e grupos aminas dos aminoácidos, resultando em compostos denominados produtos de reação de Maillard, com conseqüente diminuição acentuada na digestibilidade da proteína, em virtude do aumento nos teores de NIDA, o qual é indisponível para os microorganismos do rúmen (VAN SOEST, 1994).

Com relação à incidência de fungos (Tabela 5), verificou-se diferença significativa $(\mathrm{P}<0,05)$ entre os métodos de secagem. A ocorrência de fungos foi maior no tratamento em que a forragem não sofreu emurchecimento (T1) e naqueles em que foi amontoada (T3, T5 e T6), evidenciando que, no processo de fenação da alfafa, é necessário o emurchecimento ao sol e o material na fase de cura à sombra deve ser mantido espalhado. Essa diferença entre os tratamentos persistiu durante o tempo de armazenamento de até 60 dias.

Quanto à influência do tempo de armazenamento sobre o desenvolvimento de fungos, verifica-se maior ocorrência $(\mathrm{P}<0,05)$, no tempo zero, declinando com 15 dias e ascendendo gradativamente depois, com exceção dos tratamentos T5 (sol 60\%, A), que não apresentou efeito significativo $(\mathrm{P}<0,05)$, e T2 (sol $50 \%, \mathrm{E}$ ), que teve menor ocorrência de fungos no tempo zero e maior no armazenamento. Os gêneros dos fungos presentes no tempo zero, sem considerar a proporção de cada um, foram: Penicillium, Aspergillus, Rhizoctonia e Trichoderma, sendo o gênero Aspergillus um potente produtor de micotoxinas (MOSER, 1980).

Aos 15 e 30 dias de armazenamento, os gêneros mais comuns foram: Trichoderma, Rhizoctonia, Fusarium, Cladosporium, Nigrospora, Penicillium e Aspergillus. Houve predominância de Penicillium em todos os fenos, sendo os dois gêneros de Aspergillus mais freqüentes nos fenos provenientes dos métodos de secagem T3 (sol 50\%, A) e T5 (sol $60 \%$, A). Uma observação freqüente nas amostragens, principalmente aos 30 dias de armazenamento, foi o gênero Rhizoctonia ter sido parasitado por outros fungos, alterando a coloração das colônias. Notou-se a presença de hifas mais grossas septadas invadidas por hifas mais finas, talvez um caso de hiperparasitismo ou sintrofismo. É por intermédio desses fenômenos naturais que ocorre a mudança das populações de fungos no feno. Segundo PAPAVIZAS (1985), diversos exemplos de micoparasitismo mostram-se promissores no controle biológico, o Trichoderma sp. é um hiperparasita. Também, CHET e ELAD (1983), por meio dos estudos do parasitismo de Rhizoctonia solani por Trichoderma spp., observaram o quimiotropismo, constatando que o Trichoderma spp. detecta seu hospedeiro por intermédio do estímulo químico.

Aos 60 dias de armazenamento, os gêneros mais encontrados foram: Penicillium, Aspergillus, Rhizoctonia e Mucor.

A maior incidência de fungos no início do armazenamento deveu-se à presença de gêneros típicos de campo, que tendem a desaparecer com o armazenamento, diminuindo a sua proporção e aumentando a dos gêneros típicos do armazenamento, com conseqüente mudança nas populações de fungos com o processo do armazenamento. Estes resultados estão de acordo com os de GREGORY et al. (1963), que observaram, durante a secagem à campo, ocorrência de uma população bem diversificada de microorganismos, alguns vivendo no ar, na planta e no solo. Os saprófitas, como o Cladosporium e Alternaria, ocorrem em grande quantidade na forragem. A diversidade de propágulos presentes sugere que diferentes tipos de microflora podem se desenvolver mais tarde, de acordo com as condições que prevalecerão nos fardos ou medas em qualquer período. Também no trabalho de LACEY (1975) com gramíneas nativas, foi observada grande variedade de inóculos, derivados do solo e do ar, crescendo especificamente na planta de forma saprófita, no material morto ou senescente. A secagem lenta permite a colonização dos saprófitas, normalmente predominam Cladosporium, embora Alternaria $e$ Fusarium também sejam freqüentes.

Segundo HLODVERSSON e KASPERSSON (1986), ocorre acentuada alteração na população de fungos com o processo de fenação, havendo diminuição daqueles gêneros típicos de campo, como Fusarium 
Tabela 4 - Teor de proteína bruta (PB), fibra em detergente neutro (FDN) e fibra em detergente ácido (FDA), de folhas e caules do feno de alfafa em função dos métodos de fenação

Table 4 - Alfalfa hay leaves and stems crude protein (CP), neutral detergent fiber (NDF) and acid detergent fiber (ADF) composition concerning to the hay-making method

\begin{tabular}{|c|c|c|c|c|c|c|}
\hline \multirow[t]{2}{*}{$\begin{array}{l}\text { Métodos de fenação } \\
\text { Hay-making method }\end{array}$} & \multicolumn{3}{|c|}{$\begin{array}{l}\text { Folha } \\
\text { Leaves }\end{array}$} & \multicolumn{3}{|c|}{$\begin{array}{l}\text { Caules } \\
\text { Stems }\end{array}$} \\
\hline & $\begin{array}{l}\mathrm{PB} \\
C P\end{array}$ & $\begin{array}{l}\text { FDN } \\
N D F\end{array}$ & $\begin{array}{l}\text { FDA } \\
A D F\end{array}$ & $\begin{array}{l}\mathrm{PB} \\
C P\end{array}$ & $\begin{array}{l}\text { FDN } \\
N D F\end{array}$ & $\begin{array}{l}\text { FDA } \\
A D F\end{array}$ \\
\hline $\begin{array}{l}\text { Sombra, E } \\
\text { Shade, } S\end{array}$ & $29,16^{\mathrm{ab}}$ & $28,08^{a b}$ & $19,67^{\mathrm{a}}$ & $14,83^{\mathrm{a}}$ & $60,85^{b}$ & $49,47^{\mathrm{a}}$ \\
\hline $\begin{array}{l}\text { Sol } 50 \%, \text { E } \\
\text { Sun } 50 \%, S\end{array}$ & $29,17^{\mathrm{ab}}$ & $25,66^{\mathrm{b}}$ & $16,76^{\mathrm{b}}$ & $11,96^{\mathrm{b}}$ & $65,04^{\mathrm{ab}}$ & $55,47^{\mathrm{a}}$ \\
\hline $\begin{array}{l}\text { Sol } 50 \%, \text { A } \\
\text { Sun } 50 \%, P\end{array}$ & $30,47^{\mathrm{a}}$ & $31,01^{\mathrm{ab}}$ & $20,17^{a}$ & $11,83^{b}$ & $69,41^{\mathrm{a}}$ & $51,32^{\mathrm{a}}$ \\
\hline $\begin{array}{l}\text { Sol } 60 \%, \text { E } \\
\text { Sun } 60 \%, S\end{array}$ & $29,41^{a b}$ & $25,63^{\mathrm{b}}$ & $16,9^{4 b}$ & $13,09^{a b}$ & $67,16^{\mathrm{a}}$ & $46,56^{\mathrm{a}}$ \\
\hline $\begin{array}{l}\text { Sol } 60 \%, \text { A } \\
\text { Sun } 60 \%, P\end{array}$ & $30,46^{\mathrm{a}}$ & $28,47^{\mathrm{ab}}$ & $18,12^{\mathrm{ab}}$ & $12,24^{\mathrm{b}}$ & $68,34^{\mathrm{a}}$ & $52,50^{\mathrm{a}}$ \\
\hline $\begin{array}{l}\text { Sol } 80 \%, \text { A } \\
\text { Sun } 80 \%, P\end{array}$ & $27,63^{b}$ & $31,71^{\mathrm{a}}$ & $18,30^{\mathrm{a}}$ & $11,64^{\mathrm{b}}$ & $61,52^{\mathrm{b}}$ & $48,77^{\mathrm{a}}$ \\
\hline $\mathrm{CV} \%$ & 3,57 & 8,50 & 7,56 & 9,57 & 5,70 & 4,97 \\
\hline
\end{tabular}

Médias seguidas de letras distintas nas colunas diferem pelo teste Tukey $5 \%$.

Averages followed by different letters in the collums differ at a $5 \%$.

Tabela 5 - Médias transformadas em log x da presença de fungos (UFC/g) no feno de alfafa, em função do tempo de armazenamento

Table 5 - Averages transformed in $\log x$ in the presence of fungis in the alfalfa hay, concerning to the storage period

\begin{tabular}{|c|c|c|c|c|}
\hline \multirow[t]{2}{*}{$\begin{array}{l}\text { Métodos de fenação } \\
\text { Hay-making method }\end{array}$} & \multicolumn{4}{|c|}{$\begin{array}{l}\text { Tempo de armazenamento (dias) } \\
\text { Storage period (days) }\end{array}$} \\
\hline & 0 & 15 & 30 & 60 \\
\hline $\begin{array}{l}\text { Sombra, E } \\
\text { Shade, } S\end{array}$ & $5,9140^{1} \mathrm{aA}\left(8,4 \times 10^{5}\right)$ & $4,4115 \mathrm{cD}\left(0,26 \times 10^{5}\right)$ & $4,7163 \mathrm{cC}\left(0,52 \times 10^{5}\right)$ & $5,1133 \mathrm{bcB}\left(1,3 \times 10^{5}\right)$ \\
\hline $\begin{array}{l}\text { Sol } 50 \%, \mathrm{E} \\
\text { Sun } 50 \%, \mathrm{~S}\end{array}$ & $4,6430 \mathrm{cB}\left(0,46 \times 10^{5}\right)$ & $4,5480 \mathrm{cB}\left(0,35 \times 10^{5}\right)$ & $5,0923 \mathrm{bB}\left(1,3 \times 10^{5}\right)$ & $5,3523 \mathrm{abA}\left(2,3 \times 10^{5}\right)$ \\
\hline $\begin{array}{l}\text { Sol } 50 \%, \text { A } \\
\text { Sun } 50 \%, P\end{array}$ & $5,9383 \mathrm{aA}\left(9,5 \times 10^{5}\right)$ & $5,7173 \mathrm{aAB}\left(5,33 \times 10^{5}\right)$ & $5,4068 \mathrm{aB}\left(2,8 \times 10^{5}\right)$ & $5,6315 \mathrm{aB}\left(4,4 \times 10^{5}\right)$ \\
\hline $\begin{array}{l}\text { Sol } 60 \%, \mathrm{E} \\
\text { Sun } 60 \%, S\end{array}$ & $4,7742 \mathrm{cA}\left(0,62 \times 10^{5}\right)$ & $4,4501 \mathrm{cB}\left(0,28 \times 10^{5}\right)$ & $4,3993 \mathrm{~dB}\left(0,28 \times 10^{5}\right)$ & $4,4680 \mathrm{~dB}\left(0,3 \times 10^{5}\right)$ \\
\hline $\begin{array}{l}\text { Sol } 60 \%, \text { A } \\
\text { Sun } 60 \%, P\end{array}$ & $5,5170 \mathrm{bA}\left(3,7 \times 10^{5}\right)$ & $5,3220 \mathrm{bA}\left(2,25 \times 10^{5}\right)$ & $5,440 \mathrm{aA}\left(3 \times 10^{5}\right)$ & $5,5940 \mathrm{aA}\left(4,4 \times 10^{5}\right)$ \\
\hline $\begin{array}{l}\text { Sol } 80 \%, \text { A } \\
\text { Sun } 80 \%, P\end{array}$ & $5,8170 \mathrm{abA}\left(7 \times 10^{5}\right)$ & $4,6275 \mathrm{cB}\left(0,45 \times 10^{5}\right)$ & $4,8618 \mathrm{bcB}\left(0,7 \times 10^{5}\right)$ & $4,8185 \mathrm{cB}\left(0,7 \times 10^{5}\right)$ \\
\hline $\begin{array}{l}\text { CV }(\%)=2,97 \\
\text { d.m.s. = 0,3138; par } \\
\text { d.m.s. = 0,2822; par } \\
1 \text { Médias seguidas de }\end{array}$ & 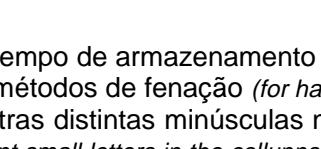 & $\begin{array}{l}\text { eriod). } \\
\text { thod). }\end{array}$ & & \\
\hline
\end{tabular}

e Cladosporium, e aumento de Aspergillus e Penicillium de maior ocorrência no armazenamento. Os fungos de armazenamento, como o Aspergillus, normalmente se desenvolvem em fenos com diferentes conteúdos de umidade, podendo servir como indicador biológico das condições de armazenamento (KASPERSSON et al., 1984).
Comparando os dados das Tabelas 2 e 3 com os da Tabela 5, verifica-se que a ocorrência de fungos não influenciou a composição bromatológica dos fenos, porém seu aspecto geral foi depreciado com coloração esbranquiçada pela presença de esporos, $o$ que certamente dificultaria a comercialização. De acordo com REES (1982), a população de fungos de 
campo, geralmente, não causa alterações acentuadas na composição química dos fenos, exceto quando os teores de umidade permanecem elevados por períodos prolongados. Mais recentemente, BOSSUYT et al. (1996) e UNDI e WITTENBERG (1996) ressaltaram que a presença de fungos no feno pode influenciar indiretamente a fermentação ruminal e, dessa forma, favorecer a digestibilidade da fibra, tendo em vista que os fungos podem causar fraturas e perfurações no xilema e nos vasos lignificados. Entretanto, MUCKet al. (1984) destacaram que o oferecimento de feno altamente mofado e a exposição à esporos fúngicos podem ser prejudiciais à saúde dos animais, especialmente ruminantes jovens (UNDI e WITTENBERG, 1996) e em eqüinos, entre os monogástricos (CUNHA, 1991), bem como às pessoas que manuseiam o feno, devido à presença de toxinas, principalmente aquelas relacionadas aos fungos patogênicos, como Aspergillus glaucus e Aspergillus fumigatus (MOSER, 1980; REIS e RODRIGUES, 1992).

\section{Conclusões}

O método de fenação mais adequado para a conservação da alfafa consistiu na exposição da forragem ao sol até a perda de 50\% do peso, com posterior secagem do material espalhado à sombra.

$\mathrm{Na}$ fase de secagem à sombra, o amontoamento não influiu na composição bromatológica, porém propiciou o desenvolvimento de fungos, depreciando o aspecto geral do feno com a presença de esporos.

\section{Referências Bibliográficas}

ALBERT, A. R., HEUBER, B., DAWIS W. L. 1989. Role of water activity in the spoilage of alfalfa hay. J. Dairy Sci., 72 (10):2573-2581.

ASSOCIATION OF OFFICIAL AGRICULTURAL CHEMISTS - AOAC. 1970. Official methods of analysis. 11.ed. Washington D.C. 1015 p.

BARNETT, H.L., HUNTER B.B. 1987. Illustrated genera of imperfect fungi. 4 ed., Macmillan Publishing Company. 241p.

BOSSUYT, C.V., WITTENBERG, K.M., CROW, G.H. 1996. Effect of fungal biomass in alfalfa hay on intake and total digestion in growing beef calves. J. Anim. Sci, 74:1336-1342.

CHET, I.J., ELAD, Y. 1996. Effect on catechrol and disodium EDTA on melanin content of hyphal and scherotial walls of sclerotium rolfsü sacc. And the role of melanin in the susceptibility of these walls to B - $(1,3)$ - Glucanase and chitenase. Soil Biology and Biochemistry, 1:131-138.

COLLINS, M., PAULSON, W.H., FINNER, M.F. et al. 1987. Moisture and storage effects on dry matter and quality losses of alfalfa in round bales. Trans. Asae, 30(4):913-917.

COSTA, C., MONTEIRO, A.L.G. 1997. Alfafa como forrageira para corte e pastejo. In: SIMPÓSIO SOBRE ECOSSISTEMA DE PASTAGENS, 3, 1997, Jaboticabal. Anais... Jaboticabal: Faculdade de Ciências Agrárias e Veterinárias, Universidade Estadual Paulista, p.297-317.
CUNHA, T.J. 1991. Horse: feeding and nutrition. 2.ed. San Diego, Califórnia: Academic Press. 445p.

GREGORY, P.H., LACEY, M.E., FESTENSTEIN, G.N. et al. 1963. Microbial and biochemical changes during the moulding of hay. J. Gen. Microbial., 33(1):147-174.

HART, R.H., BURTON, G.H. 1967. Losses and quality changes during alfalfa hay harvest and storage. Trans. Asae., 31(2):350-355.

HLODVERSSON, R., KASPERSSON, A. 1986. Nutrient losses during deterioration of hay in relation to changes in biochemical composition and microbial growth. Anim. Feed Sci. Technol., 15(2):149-165.

KALU, B.A., FICK, G.M.1983. Morphological stage of development as a predictor of alfafa herbage quality. Crop Sci., 23:1167-1172.

KASPERSSON, A., HLODVERSSON, R., PALMGREN, V, et al.1984. Microbial and biochemical changes occuring deterioration of hay and preservative effect of urea. Sweed. J. Agric. Res., 14(1):127-133.

LACEY, J.1975. Potencial hazards to animal and man from microorganisms in fodders and grain. Trans. Br. Mycol. Soc., 65(2):171-184.

LAMBERT, W.V., JANIKE, E. W. Making hay with forced air. University of Nebraska - College of Agricultural and U.S. Departament of Agriculture, s/ date. 16p. (Extension Sevice).

MERCHEN, N.R., SATTER, L.D. 1983. Changes in nitrogenous componds and sites of digestion of alfalfa harvest at different moisture contents. J. Dairy Sci., 66:789-801.

MOSER, L.C. 1980. Quality of forage as affected by postharvest storage and processing. In: Crop quality storage, and utilization. ASA/CSSA. p.227-260.

MUCK, A.P., GUYRE, P., HOL BROOK, N. 1984. Physiological functions of glicocoticoides in stress and their relation to pharmacological actions. Endocrinological Review, 5:25.

NATIONAL RESEARCH COUNCIL - NRC. 1989. Nutrients requirements of dairy cattle. National Research Council. 157p.

PAPAVIZAS, G.C. 1985. Trichoderma and gliocladium: Biologi, Ecology and potential for biocontrol. Annual Review of Phitopathology, Polo Alto, 23:23-26.

RAYMOND, F., SHEPPERSON, G., WALTHAM, R.1978. Forage conservation and feeding. 3.ed., Sulfolk: Farming Press. 208p.

REES, D.V.H. 1982 A discussion of sources of dry matter loss during the process of haymaking. J. Agric. Eng. Res., 27:469-479.

REIS, R.A., RODRIGUES, L.R. de A. Uso de conservantes em fenos com alto teor de umidade. In: SEMANA DE ZOOTECNIA, 14, 1992, Pirassununga. Anais...Pirassununga: Fundação Cargill, 1992. p.77-89.

REIS, R.A. Processamento e conservação de fenos. In: WORKSHOP SOBRE O POTENCIAL FORRAGEIRO DO GÊNERO CYNODON, 1996, Juiz de Fora. Anais...Juiz de Fora: EMBRAPA-CNPGL, 1996. p.57-68.

ROTZ, C.A., ABRAMS, S.M. 1988. Losses and quality changes durig alfalfa hay harvest and storage. Trans. Asae, 31(2):350-354.

SILVA, D.J. 1990. Análise de alimentos (Métodos químicos e biológicos). Viçosa: Imprensa Universitária da UFV. 166p.

UNDI, M., WITTENBERG, K.M. 1996. Effect of fungal biomass in mouldy alfalfa hay on preference by dairy calves with no previous exposure to mouldy feeds. J. Anim. Sci., 79(7): 1250-1254.

VAN SOEST, P.J. 1994. Nutritional ecology of the ruminant. Ithaca. Constock Publishing Associates. 476p.

Recebido em: 12/11/98 Aceito em: 29/09/99 